\title{
Cardiovascular Effects of the Combination of OPC-18790 and Dopamine in Halothane-Anesthetized Dogs
}

\author{
Shuji Itoh, Toyoki Mori*, Kenji Yoshida, Hiroyuki Fujiki, Michiaki Tominaga and Youichi Yabuuchi \\ 2nd Tokushima Institute of New Drug Research, Otsuka Pharmaceutical Co., Ltd., 463-10 Kagasuno Kawauchi-cho, Tokushima 771-01, Japan \\ Received May 8, 1995 Accepted August 29, 1995
}

\begin{abstract}
OPC-18790, ( \pm )-6-[3-(3,4-dimethoxybenzylamino)-2-hydroxypropoxy]-2(1H)-quinolinone, is a novel positive inotropic agent, and its mechanism of positive inotropic action involves not only phosphodiesterase inhibition, but also a prolongation of action potential duration in ventricular muscle. Prolongation of action potential duration is also a property of class III antiarrhythmic agents; therefore, we examined the cardiohemodynamic effects and arrhythmogenicity of a combination of OPC-18790 and dopamine in halothane-anesthetized dogs. Dopamine $(5 \mu \mathrm{g} / \mathrm{kg} / \mathrm{min})$ alone increased the peak of the first derivative of left ventricular pressure ( $\left(\mathrm{LVdP} / \mathrm{dt}_{\mathrm{max}}\right)$ and cardiac output $(\mathrm{CO})$ by $43-48 \%$ and $16-20 \%$, respectively, while OPC-18790 $(10 \mu \mathrm{g} / \mathrm{kg} / \mathrm{min})$ increased these parameters by $56 \%$ and $22 \%$, respectively. The combination of OPC-18790 $(10 \mu \mathrm{g} / \mathrm{kg} / \mathrm{min})$ and dopamine $(5 \mu \mathrm{g} / \mathrm{kg} / \mathrm{min})$ and dopamine alone at an increased dose of $10 \mu \mathrm{g} / \mathrm{kg} / \mathrm{min}$ further increased $\mathrm{LVdP} / \mathrm{dt}_{\max }$ and CO by $104-113 \%$ and $29-30 \%$, respectively. Thus, positive inotropic effects were equally observed in both groups, and the effects of OPC-18790 and dopamine seemed to be additive. The other hemodynamic effects were similar among all groups. Arrhythmias such as premature ventricular contraction developed in 5 out of 7 dogs $(71.4 \%)$ in the 10$\mu \mathrm{g} / \mathrm{kg} / \mathrm{min}$ dopamine group, while only one premature ventricular contraction was observed in 1 of 7 dogs $(14.3 \%)$ in the OPC-18790 $(10 \mu \mathrm{g} / \mathrm{kg} / \mathrm{min})$ and dopamine $(5 \mu \mathrm{g} / \mathrm{kg} / \mathrm{min})$ combination group. These results suggest that the combination of $\mathrm{OPC}-18790$ and dopamine may provide new therapeutic options for the treatment of heart failure.
\end{abstract}

Keywords: OPC-18790, Positive inotropic agent, Arrhythmogenicity, Dopamine, Halothane

OPC-18790, ( \pm )-6-[3-(3,4-dimethoxybenzylamino)-2hydroxypropoxy]-2(1H)-quinolinone, is a novel positive inotropic agent (1) that lacks direct chronotropic action and has moderate coronary vasodilatory action $(2,3)$. In whole-animal preparations, OPC-18790 increased cardiac output and contractility with little change in heart rate and blood pressure $(2,4)$. Similar effects have also been reported in experimentally-induced heart failure models; e.g., OPC-18790 increased cardiac output and decreased right atrial pressure and heart rate in canine heart-lung preparations and increased cardiac output and contractility with little change in heart rate and blood pressure in conscious dogs with right-sided heart failure (5). The cardiovascular profile of OPC-18790 seems to be different from that of pure cyclic GMP-inhibited phosphodiesterase (cGI-PDE) inhibitors such as amrinone, and the difference in cardiovascular profile may involve

\footnotetext{
* To whom correspondence should be addressed.
}

differences in mechanism of action. It has been reported that the mechanism of positive inotropic action of OPC18790 involves not only cGI-PDE inhibition $(2,6)$ and a cyclic AMP increase (7), but also a prolongation of action potential duration in ventricular cells (2). In contrast, amrinone never prolongs action potential duration (8).

On the other hand, the mechanism of inotropic action of catecholamines is thought to be an increase in intracellular cyclic AMP levels via the $\beta_{1}$-adrenoceptor G-protein adenylate-cyclase system. Catecholamines are widely used as potent positive inotropic agents, but their clinical usefulness is limited by their positive chronotropic and arrhythmogenic activities and by a development of drug tolerance due to $\beta_{1}$-adrenoceptor down-regulation.

It is of interest to examine the interaction of these positive inotropic agents having different mechanisms. Recently, Wu et al. (9) reported that a high dose of OPC$18790(3 \mathrm{mg} / \mathrm{kg}, \mathrm{i} . \mathrm{v}$.$) , similar to other drugs which in-$ crease calcium inward current, worsened halothane- 
adrenaline-induced ventricular tachyarrhythmias in dogs. However, a low lose of OPC-18790 $(0.3 \mathrm{mg} / \mathrm{kg}$, i.v. $)$ did not aggravate the arrhythmia. Therefore, in this study we examined the cardiovascular effects of clinical dosages of OPC-18790 and dopamine, which is clinically a most popular catecholamine, in order to answer the following questions: 1) What cardiovascular actions of OPC-18790 and catecholamines are affected when the two drugs are used in combination? 2) Is the arrhythmogenicity of catecholamines enhanced by OPC-18790? 3) Is the combination of OPC-18790 and dopamine more beneficial in heart failure treatment than dopamine alone? We chose halothane-anesthetized dogs as an animal model, since halothane depresses cardiac contractility (10) and acts to increase the arrhythmogenicity of catecholamines (11-13).

\section{MATERIALS AND METHODS}

\section{Animal preparations}

Twenty-eight healthy mongrel dogs of either gender, weighing $9.5-12.5 \mathrm{~kg}$, were anesthetized with thiopentone sodium $(30 \mathrm{mg} / \mathrm{kg}$, i.v.). After endotracheal intubation and ventilation with a respirator (SN-480-3; Shinano, Tokyo), the dogs were anesthetized with $1.0-1.5 \%$ halothane in $50 \%$ oxygen volatilized by a precision vaporizer (Compact-18; Kimura Ika Kikai, Tokyo). A femoral artery and two femoral veins were cannulated for pulsatile blood pressure measurement and for infusion of test drugs or solvent, respectively. A 4F Millar microtip transducer (MPC-500; Millar Instruments, Houston, TX, USA) for measurement of left ventricular pressure (LVP) was inserted through the left carotid artery into the left ventricular chamber. A 5F Swan-Ganz thermodilution cardiac output catheter (VS0693; Nihon Kohden, Tokyo) was placed in the pulmonary artery through the left external jugular vein in order to measure cardiac output. A lactate Ringer's solution was infused via a femoral vein at a rate of $6 \mathrm{ml} / \mathrm{kg} / \mathrm{hr}$ throughout the experiment. LVP, the first derivative of LVP, blood pressure and heart rate, which was counted with a tachometer triggered by blood pressure pulse waves, were measured by a polygraph system (Polygraph; NEC-San-ei, Tokyo) and recorded with a thermal-pen recorder (Recti-Horiz 8K, NEC-San-ei). The lead II ECG was recorded by a thermal-pen recorder (Cardio Logger 322, NEC-San-ei) throughout the experiment. The peak of the first derivative of LVP (LVdP $\left./ \mathrm{dt}_{\max }\right)$ was used as an index of cardiac contractility.

\section{Protocol}

After at least a 15 -min rest for stabilization after the preparations were set up, baseline hemodynamic variables and cardiac output were measured. The dogs were then randomly divided into four groups. Figure 1 shows the protocol of this experiment. In Group 1, dopamine ( 5 $\mu \mathrm{g} / \mathrm{kg} / \mathrm{min}$ ) infusion was continued for $90 \mathrm{~min}$. Thirty minutes after the start of the administration of dopamine, a $5 \%$ glucose solution $(10 \mathrm{ml} / \mathrm{hr})$, as the placebo of OPC-18790, was infused for $30 \mathrm{~min}$. In Group 2, the experimental protocol was the same as in Group 1, except for the administration of OPC-18790 $(10 \mu \mathrm{g} / \mathrm{kg} / \mathrm{min})$ instead of the $5 \%$ glucose solution. In Group 3, each dog was infused with dopamine at 5,10 and $5 \mu \mathrm{g} / \mathrm{kg} / \mathrm{min}$, in that order, for $30 \mathrm{~min}$ each. In Group 4, OPC-18790 (10 $\mu \mathrm{g} / \mathrm{kg} / \mathrm{min}$ ) was infused for $90 \mathrm{~min}$, and then dopamine (5 $\mu \mathrm{g} / \mathrm{kg} / \mathrm{min}$ ) was added during the second $30 \mathrm{~min}$ period.

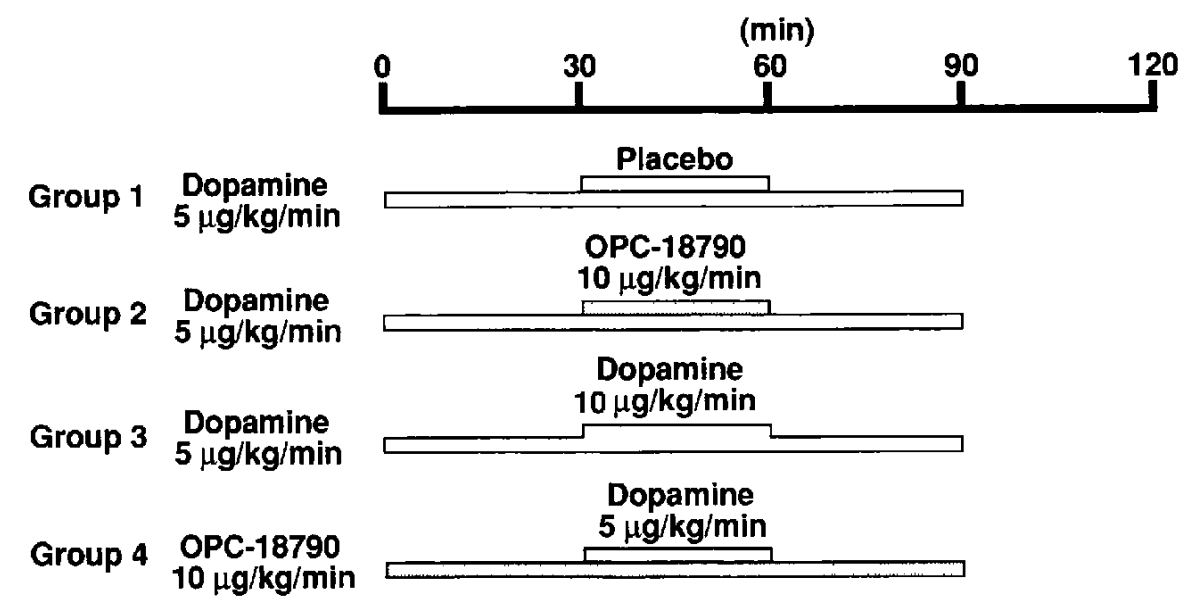

Fig. 1. Study protocol of combined use of OPC-18790 and dopamine in halothane-anesthetized dogs. Drugs were administered as follows: $5 \mu \mathrm{g} / \mathrm{kg} / \mathrm{min}$ of dopamine and placebo $(10 \mathrm{ml} / \mathrm{hr}$ of $5 \%$ glucose solution) for $90 \mathrm{~min}$ in Group 1 , $5 \mu \mathrm{g} / \mathrm{kg} / \mathrm{min}$ of dopamine plus $10 \mu \mathrm{g} / \mathrm{kg} / \mathrm{min}$ of OPC-18790 in Group 2, 5 and $10 \mu \mathrm{g} / \mathrm{kg} / \mathrm{min}$ of dopamine in Group 3 , $10 \mu \mathrm{g} / \mathrm{kg} / \mathrm{min}$ of OPC -18790 plus $5 \mu \mathrm{g} / \mathrm{kg} / \mathrm{min}$ of dopamine in Group 4. 
Table 1. Basal values for the peak of the first derivative of left ventricular pressure ( $\mathrm{LVdP} / \mathrm{dt}_{\mathrm{max}}$ ), cardiac output (CO), heart rate (HR) and mean arterial blood pressure (mBP) in each group

\begin{tabular}{llcccc}
\hline & & Group 1 & Group 2 & Group 3 & Group 4 \\
\hline $\mathrm{LVdP} / \mathrm{dt}_{\max }$ & $(\mathrm{mmHg} / \mathrm{sec})$ & $1420 \pm 60$ & $1680 \pm 130$ & $1690 \pm 130$ & $1450 \pm 70$ \\
$\mathrm{CO}$ & $(1 / \mathrm{min})$ & $1.20 \pm 0.09$ & $1.42 \pm 0.11$ & $1.37 \pm 0.13$ & $1.17 \pm 0.05$ \\
$\mathrm{HR}$ & (beats $/ \mathrm{min})$ & $122 \pm 3.9$ & $120 \pm 4.9$ & $115 \pm 6.5$ & $109 \pm 7.5$ \\
$\mathrm{mBP}$ & $(\mathrm{mmHg})$ & $87.6 \pm 3.7$ & $91.6 \pm 5.1$ & $85.5 \pm 5.4$ & $87.3 \pm 3.3$ \\
\hline
\end{tabular}

Each value represents the mean \pm S.E.M. of 7 dogs. There were no significant differences between the four group.

In all groups, measurements were continued for an additional $\mathbf{3 0}$ min after drug treatment was stopped. Cardiac output was measured every $30 \mathrm{~min}$ after the start of drug administration, and the values were determined as an average of 2 to 4 thermodilution measurements. The other hemodynamic parameters were recorded at $2,5,10$, 20 and 30 min after each measurement of cardiac output.

\section{Statistics}

Data are expressed as means \pm S.E.M. The values in all

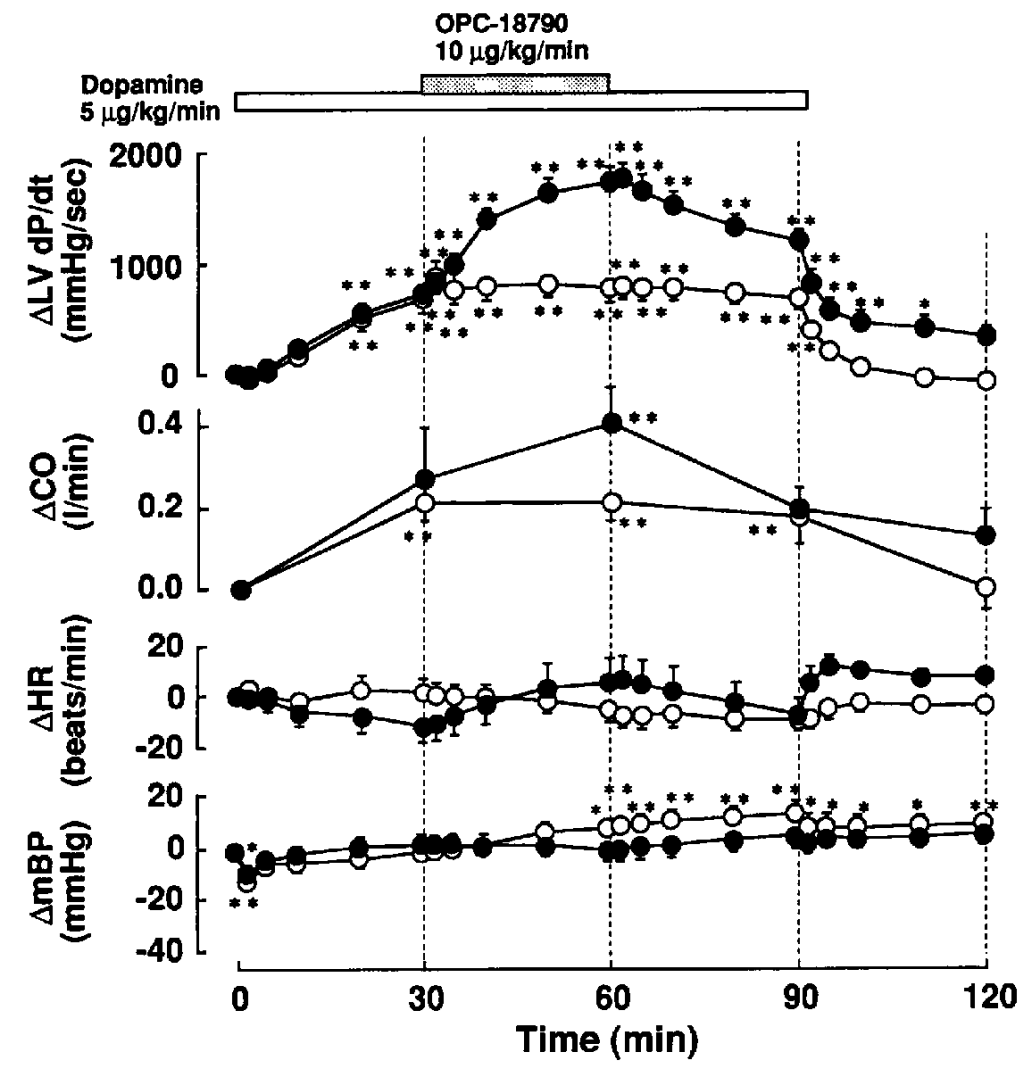

Fig. 2. Hemodynamic effects of intravenous infusion of $5 \mu \mathrm{g} / \mathrm{kg} / \mathrm{min}$ of dopamine (Group 1, open circles) and combination of $5 \mu \mathrm{g} / \mathrm{kg} / \mathrm{min}$ of dopamine and $10 \mu \mathrm{g} / \mathrm{kg} / \mathrm{min}$ of OPC-18790 (Group 2, closed circles) on the peak of the first derivative of left ventricular pressure ( $\left.\mathrm{LVdP} / \mathrm{dt}_{\mathrm{max}}\right)$, cardiac output $(\mathrm{CO})$, heart rate (HR) and mean arterial blood pressure (mBP) in halothane-anesthetized dogs. Gray and white bars represent infusions of $10 \mu \mathrm{g} / \mathrm{kg} / \mathrm{min}$ of OPC-18790 and $5 \mu \mathrm{g} / \mathrm{kg} / \mathrm{min} \mathrm{of}$ dopamine, respectively. Data points each represent the mean \pm S.E.M. of 7 dogs. ${ }^{*} \mathrm{P}<0.05$ and ${ }^{* *} \mathrm{P}<0.01$, compared with the respective basal values. ANOVA (repeated measurements) between Groups 1 and 2 showed significant differences in the values (statistical main effects) during 30-120 min of $\mathrm{LVdP} / \mathrm{dt}_{\max }(\mathrm{P}<0.01), 60-120 \mathrm{~min}$ of $\mathrm{CO}(\mathrm{P}<0.05)$ and time-dependent changes (statistical interaction effects) during 30-90 min of $\mathrm{LVdP} / \mathrm{dt}_{\max }(\mathrm{P}<0.01), 60-90 \mathrm{~min}$ of $\mathrm{CO}(\mathrm{P}<0.05), 30-60 \mathrm{~min}$ of $\mathrm{HR}(\mathrm{P}<0.01)$ and $30-60 \mathrm{~min}$ of $\mathrm{mBP}(\mathrm{P}<0.01)$. 


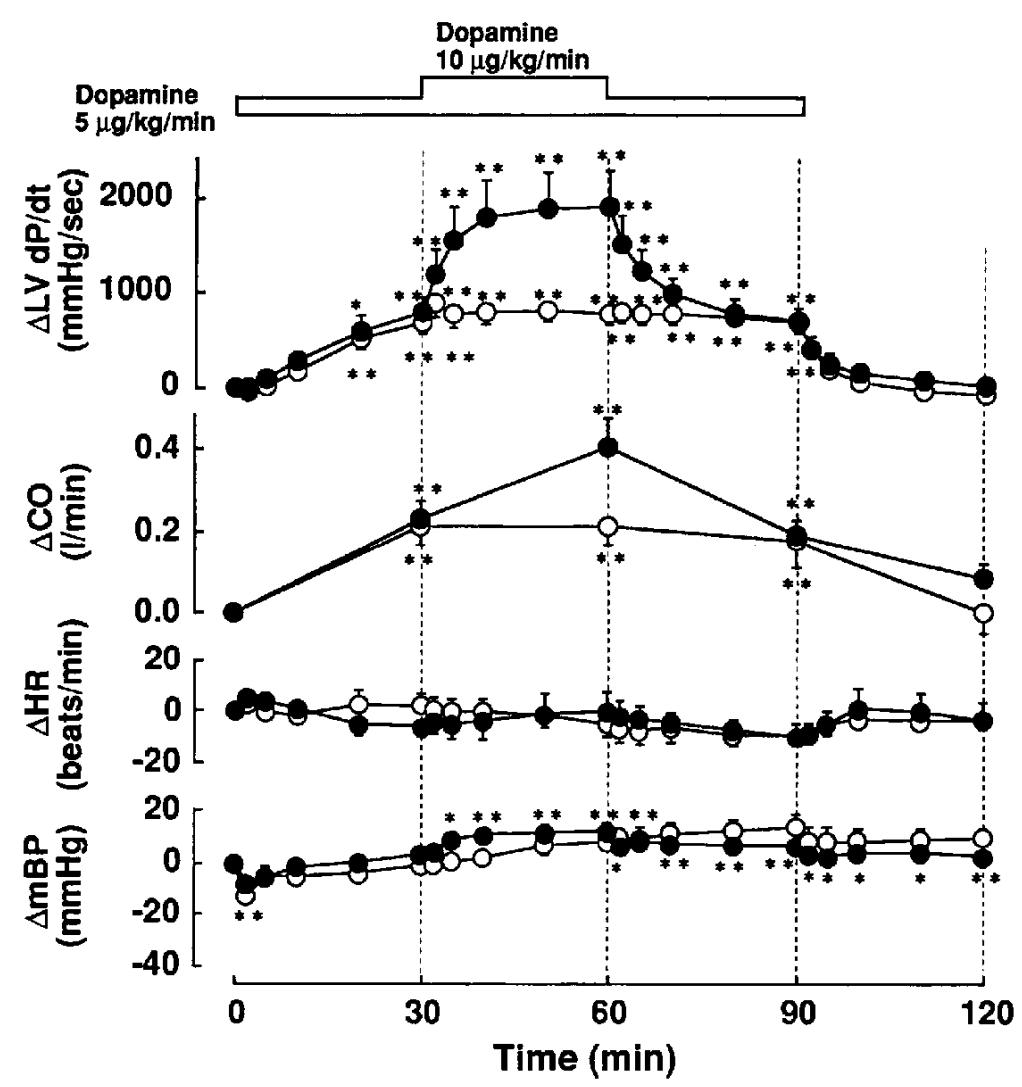

Fig. 3. Hemodynamic effects of intravenous infusion of $5 \mu \mathrm{g} / \mathrm{kg} / \mathrm{min}$ of dopamine (Group 1, open circles) and increasing the dosage of dopamine from 5 to $10 \mu \mathrm{g} / \mathrm{kg} / \mathrm{min}$ (Group 3, closed circles) on the peak of the first derivative of left ventricular pressure ( $\left(\mathrm{LVdP} / \mathrm{dt}_{\max }\right)$, cardiac output $(\mathrm{CO})$, heart rate $(\mathrm{HR})$ and mean arterial blood pressure $(\mathrm{mBP})$ in halothane-anesthetized dogs. White bars represent an infusion of dopamine. Data points each represent the mean \pm S.E.M. of 7 dogs. ${ }^{*} \mathrm{P}<0.05$ and ${ }^{* *} \mathbf{P}<0.01$, compared with the respective basal values. ANOVA (repeated measurements) between Groups 1 and 3 showed significant differences in the values (statistical main effects) during $30-60 \mathrm{~min}$ of $\mathrm{LVdP} / \mathrm{dt}_{\max }(\mathrm{P}<0.05)$ and time-dependent changes (statistical interaction effects) during 30-90 min of $\mathrm{LVdP} / \mathrm{dt}_{\max }(\mathrm{P}<0.01), 30-90 \mathrm{~min}$ of $\mathrm{CO}(\mathrm{P}<0.01)$ and $60-90 \mathrm{~min}$ of $\mathrm{mBP}(\mathrm{P}<0.01)$.

groups were compared by ANOVA (repeated measurements) and multiple comparison (Tukey's or Dunnett's method) using a software package (Statistical Analysis System; SAS Institute Japan Ltd., Tokyo). When P values were 0.05 or less, they were considered to be statistically significant.

\section{Drugs}

The drugs used in this experiment were OPC- 18790 (Otsuka Pharmaceutical Co., Tokyo) and dopamine (Inovan ${ }^{(\mathbb{8}}$; Kyowa Hakko Co., Tokyo), and both compounds were dissolved in $5 \%$ glucose solution before use.

\section{RESULTS}

The basal values for the peak of the first derivative of left ventricular pressure ( $\left.\mathrm{LVdP} / \mathrm{dt}_{\max }\right)$, which is an index of cardiac contractility, cardiac output (CO), heart rate (HR) and mean arterial blood pressure ( $\mathrm{mBP}$ ) are shown in Table 1. There were no significant differences in these parameters among the four treatment groups.

\section{Cardiovascular effects of dopamine}

Infusion of dopamine alone at $5 \mu \mathrm{g} / \mathrm{kg} / \mathrm{min}$ for $30 \mathrm{~min}$ in Groups $1-3$ produced a gradual increase in $\mathrm{LVdP}$ $/ \mathrm{dt}_{\max }$ (Figs. 2 and 3, first $30 \mathrm{~min}$ ), and $\mathrm{LVdP} / \mathrm{dt}$ and $\mathrm{CO}$ were significantly increased by $44-48 \%$ and $16-19 \%$, respectively, at $30 \mathrm{~min}$ after the start of infusion. Also observed was a transient decrease followed by an increase in arterial blood pressure (Figs. 2 and 3, first $30 \mathrm{~min}$ ). At $30 \mathrm{~min}$ after the start of dopamine infusion, changes in HR and mBP were not significant (Figs. 2 and 3, and summarized Fig. 5). As indicated in the results for Group $1, \mathrm{LVdP} / \mathrm{dt}_{\max }$ and $\mathrm{CO}$ increased by $53.9 \pm 7.2 \%$ and $19.3 \pm 5.0 \%$, respectively, at $60 \mathrm{~min}$ (Fig. 5 ), and the positive inotropic effect of dopamine remained stable from 30 to 90 min after the start of infusion (Figs. 2 and 3 , open circles). The increase in mBP became significant 


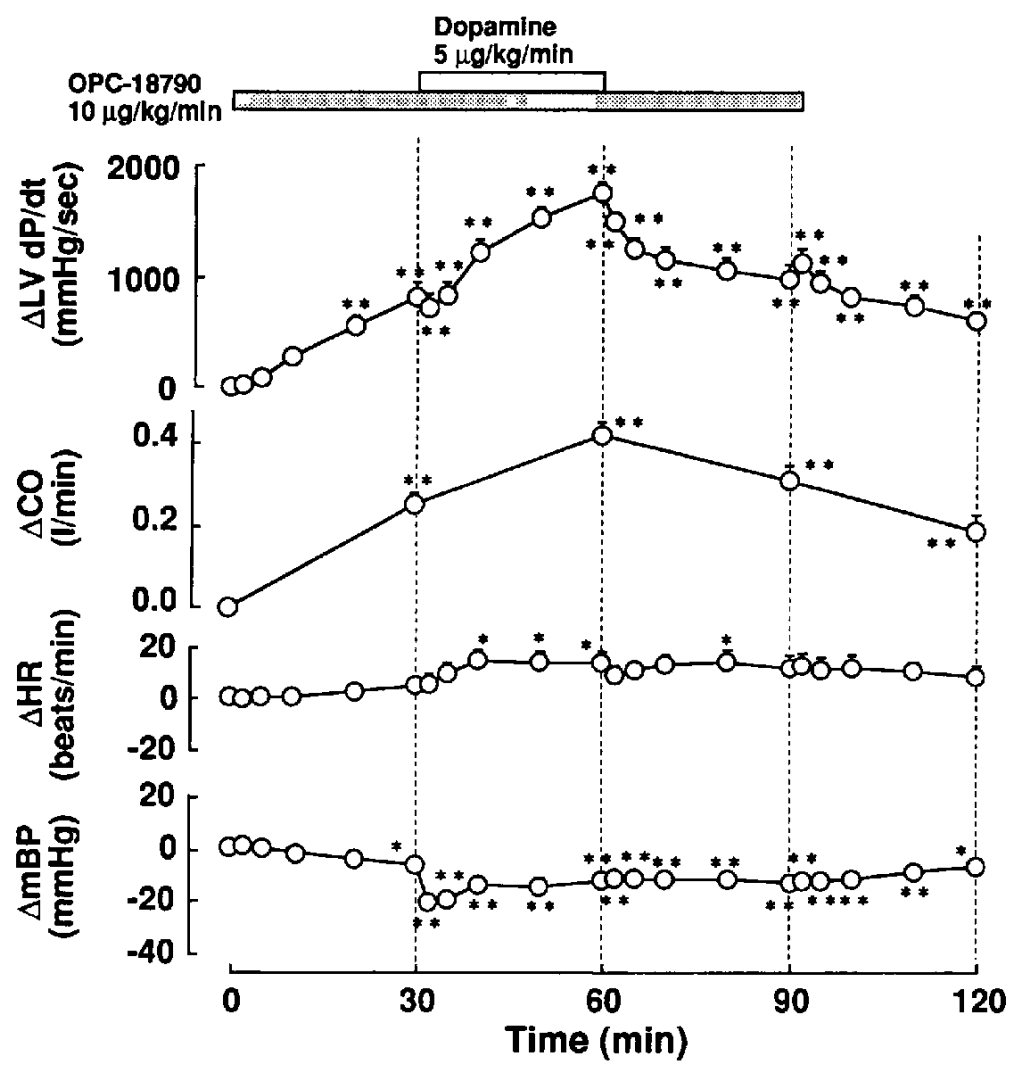

Fig. 4. Hemodynamic effects of intravenous infusion of $10 \mu \mathrm{g} / \mathrm{kg} / \mathrm{min}$ of OPC-18790 and combination of OPC-18790 and 5 $\mu \mathrm{g} / \mathrm{kg} / \mathrm{min}$ of dopamine (Group 4, open circles) on the peak of the first derivative of left ventricular pressure ( $\mathrm{LVdP} / \mathrm{dt}_{\max }$ ), cardiac output $(\mathrm{CO})$, heart rate (HR) and mean arterial blood pressure (mBP) in halothane-anesthetized dogs. Gray and white bars represent infusions of $10 \mu \mathrm{g} / \mathrm{kg} / \mathrm{min}$ of OPC-18790 and $5 \mu \mathrm{g} / \mathrm{kg} / \mathrm{min}$ of dopamine, respectively. Data points each represent the mean \pm S.E.M. of 7 dogs. ${ }^{*} \mathrm{P}<0.05$ and ${ }^{* *} \mathrm{P}<0.01$, compared with the respective basal values.

at $60 \mathrm{~min}$ (Fig. 5).

An increase in the dopamine dosage from $5 \mu \mathrm{g} / \mathrm{kg} / \mathrm{min}$ to $10 \mu \mathrm{g} / \mathrm{kg} / \mathrm{min}$ (Group 3) produced a further increase in $\mathrm{LVdP} / \mathrm{dt}_{\max }$ by $113.3 \pm 17 \%$, in CO by $29.7 \pm 4.8 \%$ and in $\mathrm{mBP}$ by $12.1 \pm 3.3 \mathrm{mmHg}$, respectively (Fig. 3, closed circles and Fig. 5). After the dosage increase was discontinued, the effects rapidly diminished; and at $30 \mathrm{~min}$ after dopamine infusion was stopped, the increase in LVdP $/ \mathrm{dt}_{\max }$ had almost disappeared $(-4.5 \pm 4.1 \%$ in Group 1 and $1.1 \pm 4.6 \%$ in Group 3).

\section{Cardiovascular effects of $O P C-18790$}

Figure 4 shows the hemodynamic effects of OPC-18790 alone (Group 4, first $30 \mathrm{~min}$ ) on $\mathrm{LVdP} / \mathrm{dt}_{\max }, \mathrm{CO}, \mathrm{HR}$ and $\mathrm{mBP}$. At $30 \mathrm{~min}$ after the administration of OPC$18790, \mathrm{LVdP} / \mathrm{dt}_{\max }$ and $\mathrm{CO}$ were significantly increased by $55.8 \pm 7.0 \%$ and $21.5 \pm 2.7 \%$, respectively, and $\mathrm{mBP}$ was decreased by $6.7 \pm 1.6 \mathrm{mmHg}$. The change in $\mathrm{HR}$ was not significant (Fig. 5).

Cardiovascular effects of combined use of OPC-18790 and dopamine
When OPC-18790 at a dose of $10 \mu \mathrm{g} / \mathrm{kg} / \mathrm{min}$ for 30 min was added after the initial $30 \mathrm{~min}$ of treatment with dopamine (Group 2), LVdP/ $\mathrm{dt}_{\max }$ was significantly increased by $104.0 \pm 5.6 \%$ (Figs. 2 and 5). As shown in Figs. 2 and 3, the change in $\mathrm{LVdP} / \mathrm{dt}_{\max }$ was slower in Group 2 (combination of OPC-18790 with dopamine) than in Group 3 (increased dopamine dose). $\mathrm{CO}$ was also significantly increased by $29.0 \pm 6.6 \%$ in Group 2 compared with Group $1(19.3 \pm 5.0 \%)$. By combination of OPC-18790 with dopamine for a 30-min period in Group $2, \mathrm{HR}$ and $\mathrm{mBP}$ were increased by $5.1 \pm 9.2$ beats $/ \mathrm{min}$ and $0.1 \pm 4.6 \mathrm{mmHg}$, respectively, but these changes were not significant. At $30 \mathrm{~min}$ after all infusion had finished, $\mathrm{LVdP} / \mathrm{dt}_{\max }$ was significantly higher $(18.9 \pm 5.1 \%)$ in Group 2 than in Groups 1 and $3(-4.5 \pm 4.1 \%$ and $1.1 \pm 4.6 \%$, respectively).

When dopamine at a dose of $5 \mu \mathrm{g} / \mathrm{kg} / \mathrm{min}$ was added after the first $30 \mathrm{~min}$ of treatment with OPC-18790 (Group 4), $\mathrm{LVdP} / \mathrm{dt}_{\max }$ was significantly increased $(121.8 \pm 6.9 \%)$ compared with Group $1(53.9 \pm 7.2 \%)$, and $\mathrm{CO}$ was also significantly increased by $35.8 \pm 1.3 \%$ (Fig. 4). By the combined use of dopamine and OPC- 

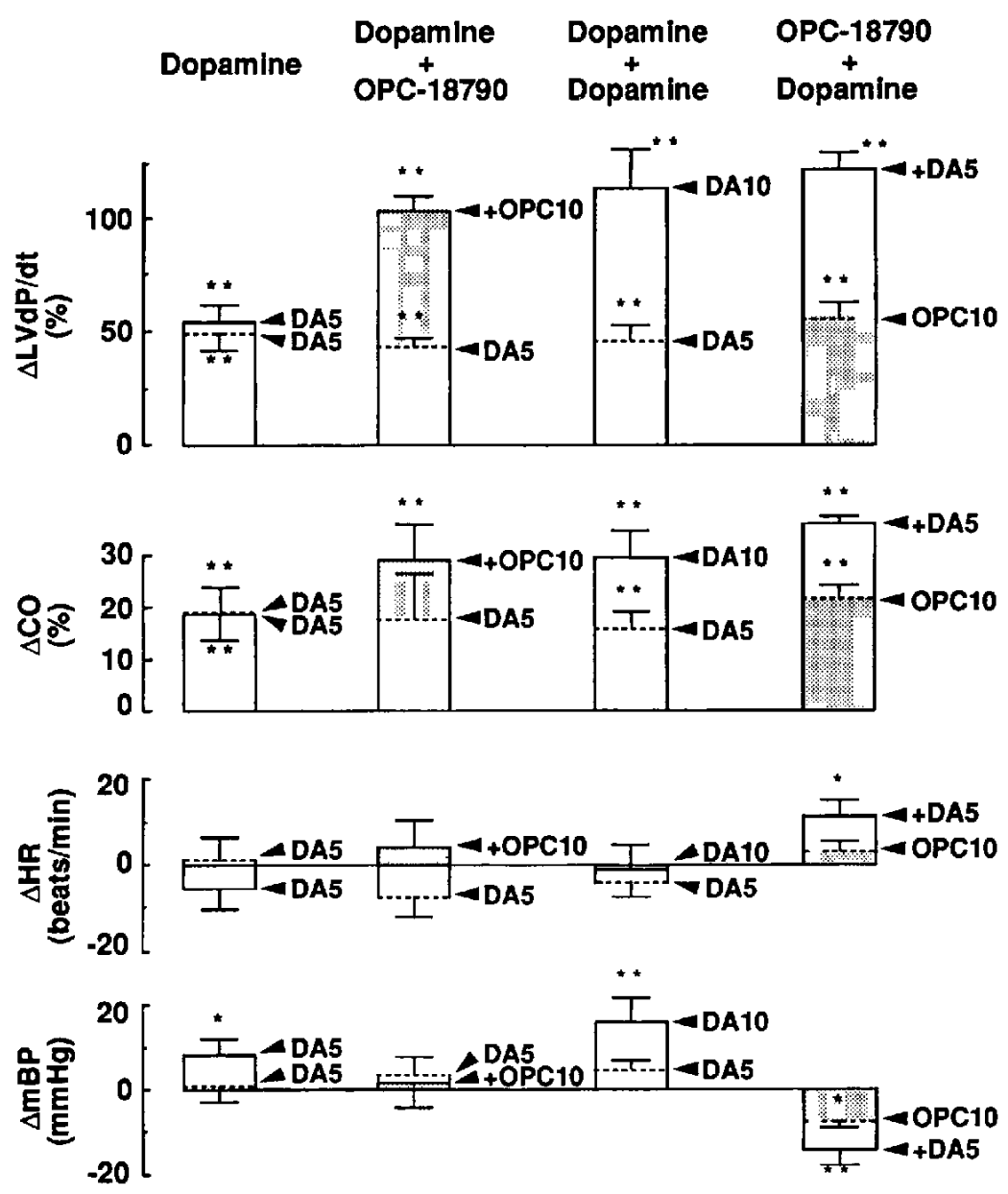

Fig. 5. Summary of hemodynamic effects of $5 \mu \mathrm{g} / \mathrm{kg} / \mathrm{min}$ of dopamine alone, combination of $5 \mu \mathrm{g} / \mathrm{kg} / \mathrm{min}$ of dopamine and $10 \mu \mathrm{g} / \mathrm{kg} / \mathrm{min}$ of OPC-18790, increase in the dopamine dosage from 5 to $10 \mu \mathrm{g} / \mathrm{kg} / \mathrm{min}$ and combination of $10 \mu \mathrm{g} / \mathrm{kg} / \mathrm{min}$ of OPC-18790 and $5 \mu \mathrm{g} / \mathrm{kg} / \mathrm{min}$ of dopamine on the peak of the first derivative of left ventricular pressure ( $\mathrm{LVdP} / \mathrm{dt} t_{\max }$ ), cardiac output (CO), heart rate (HR) and mean arterial blood pressure (mBP) 30 (dotted line) and 60 min after the start of infusion in halothane-anesthetized dogs. Gray and white bars represent infusions of $10 \mu \mathrm{g} / \mathrm{kg} / \mathrm{min}$ of OPC-18790 and dopamine, respectively. Data points each represent the mean \pm S.E.M. of 7 dogs. DA5: Dopamine at $5 \mu \mathrm{g} / \mathrm{kg} / \mathrm{min}$, DA10: Dopamine at 10 $\mu \mathrm{g} / \mathrm{kg} / \mathrm{min}, \mathrm{DA} 5+$ OPC10: Dopamine at $5 \mu \mathrm{g} / \mathrm{kg} / \mathrm{min}$ plus OPC-18790 at $10 \mu \mathrm{g} / \mathrm{kg} / \mathrm{min}$, OPC10+DA5: OPC-18790 at 10 $\mu \mathrm{g} / \mathrm{kg} / \mathrm{min}$ plus dopamine at $5 \mu \mathrm{g} / \mathrm{kg} / \mathrm{min}$. ${ }^{*} \mathrm{P}<0.05$ and ${ }^{* *} \mathrm{P}<0.01$, compared with the respective basal values.

18790 for $30 \mathrm{~min}$ in Group 4, HR was increased by $13.1 \pm 4.3$ beats $/ \mathrm{min}$ and $\mathrm{mBP}$ was decreased by $12.8 \pm$ $3.1 \mathrm{mmHg}$, and these changes were significant. After the combined use was stopped, $\mathrm{LVdP} / \mathrm{dt}_{\max }$ decreased more slowly than it did after infusion at the increased dopamine dose. At the end of the protocol, $\mathrm{LVdP} / \mathrm{dt}$ was significantly higher $(41.9 \pm 6.3 \%)$ in Group 4 than in Groups 1 and 3.

The peak hemodynamic effects of $5 \mu \mathrm{g} / \mathrm{kg} / \mathrm{min}$ of dopamine alone, combination of $5 \mu \mathrm{g} / \mathrm{kg} / \mathrm{min}$ of dopamine and $10 \mu \mathrm{g} / \mathrm{kg} / \mathrm{min}$ of OPC-18790, increase in dopamine dosage from 5 to $10 \mu \mathrm{g} / \mathrm{kg} / \mathrm{min}$ and combination of $10 \mu \mathrm{g} / \mathrm{kg} / \mathrm{min}$ of OPC-18790 and $5 \mu \mathrm{g} / \mathrm{kg} / \mathrm{min}$ of dopamine are summarized in the Fig. 5.

\section{Incidence and severity of arrhythmias}

Figure 6 shows the development of arrhythmias in each group during the entire experimental period. During the time period of $30-60 \mathrm{~min}$ (combination or dose increased), ventricular arrhythmias were observed in 4 of 7 dogs during the increase in the dopamine dose (Group 3), in 2 of 7 dogs each in Groups 1 and 4 but in 0 of 7 dogs in Group 2 during the combination dosing of OPC-18790 and dopamine. During the entire dosing time (0-90 min) ventricular arrhythmias were observed in 5 of 7 dogs $(71.4 \%)$ in Group 3, in 2 of 7 dogs $(28.6 \%)$ each in Groups 1 and 4, and in 1 of 7 dogs (14.3\%) in Group 2 (Fig. 6a). ECG records of the most severe case in Group 2 (upper) and Group 3 (lower) are shown in Fig 6b. Frequent ventricular arrhythmias occurred in 2 of 7 dogs in 
(a)

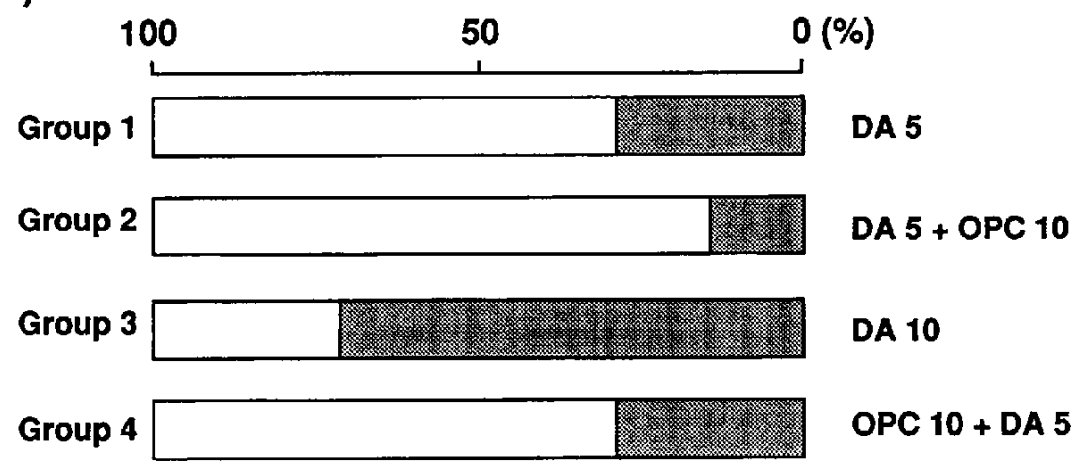

(b)
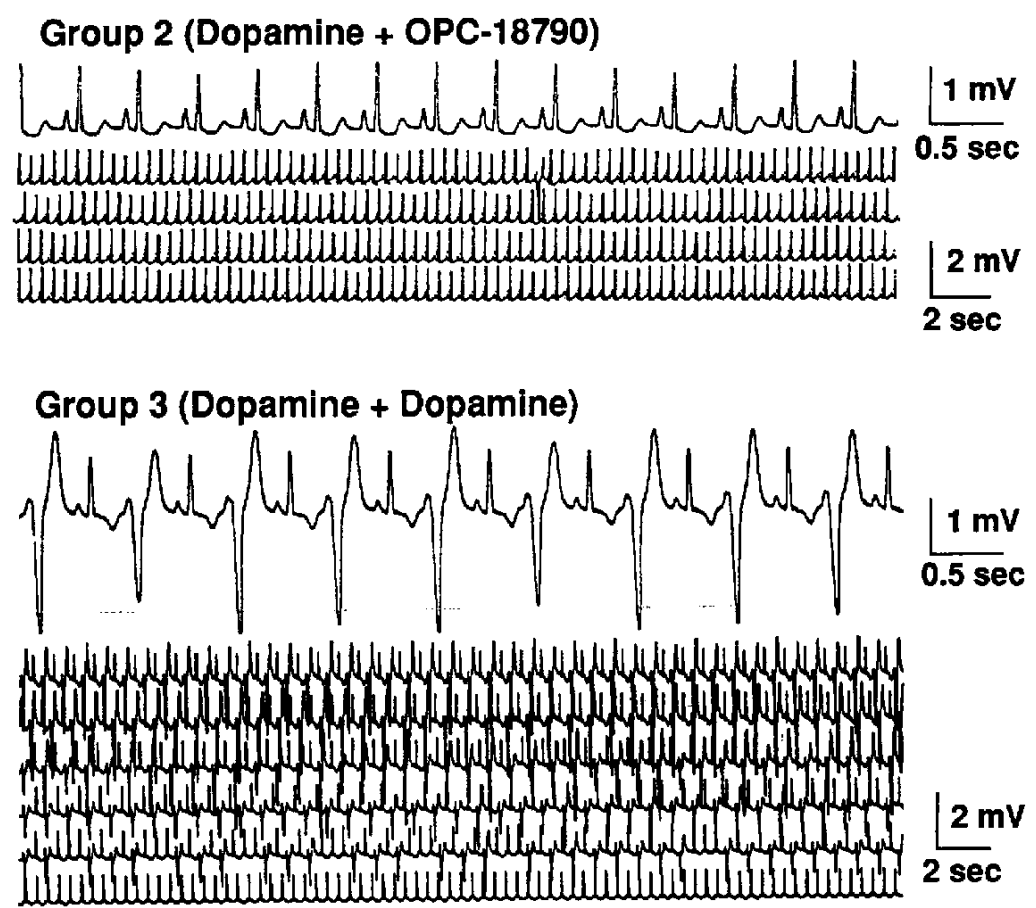

Fig. 6. Development of arrhythmia by treatment with dopamine and with a combination of OPC-18790 and dopamine in halothane-anesthetized dogs. a: Incidence of arrhythmia: Each gray column shows dogs with ventricular arrhythmia, and each open column shows dogs without arrhythmia. b: Electrocardiogram (ECG) of the most severe case from 7 observations each in Group 2 (upper) and Group 3 (lower). The sequence of the records flows from bottom to top.

Group 3, and the systolic blood pressure in these 2 dogs was higher than that in any of the other dogs.

\section{DISCUSSION}

In the present study, the effects of OPC-18790 (10 $\mu \mathrm{g} / \mathrm{kg} / \mathrm{min}$ ) infusion alone (Group 4 at $30 \mathrm{~min}$ ) on $\mathrm{LVdP} / \mathrm{dt}_{\max }$ and $\mathrm{CO}$ were similar to those of dopamine (5 $\mu \mathrm{g} / \mathrm{kg} / \mathrm{min}$ ) infusion (Groups $1-3$ at $30 \mathrm{~min}$ ). Dopamine transiently decreased $\mathrm{mBP}$ at the start of infusion and then gradually increased $\mathrm{mBP}$. This can be explained by the findings that at low doses, dopamine stimulates the $\mathrm{DA}_{1}$ dopaminergic receptors that mediate vasodilation and that at high doses, it stimulates the $\alpha$-adrenoceptors that mediate vasoconstriction (14). On the other hand, OPC-18790 tended to decrease mBP during infusion. HR was not changed by either dopamine or OPC-18790 infusion. These changes in hemodynamic parameters after OPC- 18790 infusion at $10 \mu \mathrm{g} / \mathrm{kg} / \mathrm{min}$ indicate that the drug has a selective positive inotropic action but minimal chronotropic and vasodilatory actions. This observation is in agreement with previous findings in normal con- 
scious dogs (2) and in dogs with experimentally-induced heart failure (5).

The combination of OPC-18790 and dopamine in Groups 2 and 4 increased $\mathrm{LVdP} / \mathrm{dt}_{\max }$ and $\mathrm{CO}$ to almost the same extent as the infusion of dopamine at the high dose $(10 \mu \mathrm{g} / \mathrm{kg} / \mathrm{min})$. The changes in $\mathrm{mBP}$ and $\mathrm{HR}$ were similar to those after the administration of either OPC18790 or dopamine alone. These results suggest that the cardiohemodynamic effects of OPC-18790 may not be affected by combination with dopamine and that combined use of OPC-18790 and dopamine might be comparable to increasing the dopamine dosage as far as cardiohemodynamic effects are concerned.

In contrast to the cardiohemodynamic effects, the arrhythmogenic action of dopamine at the high dose (10 $\mu \mathrm{g} / \mathrm{kg} / \mathrm{min}$ ) tended to be stronger than that of the combined use of OPC-18790 and dopamine (Fig. 6). Sato et al. (13) reported that ventricular arrhythmias were produced by dopamine infusion at doses of $5 \mu \mathrm{g} / \mathrm{kg} / \mathrm{min}$ and above in halothane-anesthetized dogs. Our results concerning the arrhythmogenicity of dopamine are in agreement with this finding. Catecholamines produce ventricular arrhythmias, which disappear by administration of $\beta$-blockers such as propranolol $(15,16)$, and this suggests that the genesis of arrhythmias is related to a $\beta$ receptor stimulation cascade. Recently, Katz (17) suggested that any drug that elevates the myocardial cyclic AMP might present the risk of arrhythmias by increasing calcium ions in the myocardium, and Hashimoto et al. (16) suggested that halothane-adrenaline arrhythmia was dependent on calcium channel activation. Since OPC-18790 increases the myocardial cyclic AMP level (7) through cGI-PDE inhibition $(2,6)$, OPC-18790 might be expected to enhance the inotropic and arrhythmogenic actions of dopamine. However, the results of this study indicate that while the positive inotropic effect of the combined use of these agents was additive (Fig. 6), the combination produced a lower incidence of arrhythmias than the increased dose of dopamine which exerted the same level of inotropic stimulation (Fig. 5). Although the chemical structure of OPC-18790 is somewhat similar to that of a $\beta$-blocker, the $\mathrm{IC}_{50}$ value of OPC-18790 in binding to $\beta$ receptor ligands is greater than $10{ }^{4} \mathrm{M}$ (our unpublished data). Therefore, the results can not be explained by the $\beta$-blocking action of OPC-18790. OPC- 18790 and class III antiarrhythmic drugs share the action potential prolonging property (2), which may be able to overcome the arrhythmogenic action due to the accumulation of intracellular cyclic AMP and calcium ions.

However, a recent study indicates that Class III agents, E-4031 and $d$-sotalol, did not exert antiarrhythmic action on the halothane-adrenaline arrhythmia in dogs (18). Therefore, there may be another interpretation of the present results. High doses of dopamine may produce cardiac ischemia and increase the occurrence of arrhythmias as a result of a decrease in coronary flow by coronary vascular $\alpha$-adrenoceptor stimulation (14) when oxygen demand is increased by its inotropic action. In the present study, frequent ventricular arrhythmias were observed in 2 of 7 dogs given dopamine at the high dose (10 $\mu \mathrm{g} / \mathrm{kg} / \mathrm{min}$ ), and these 2 dogs showed a larger increase in blood pressure than the other 5 dogs with premature ventricular contractions or without arrhythmias. These results suggest that ventricular arrhythmias may occur mainly as a result of stimulation of vascular $\alpha$ adrenoceptors as well as stimulation of cardiac $\alpha$ - and $\beta$ adrenoceptor. Thandroyen et al. (15) reported that a variety of $\alpha$-adrenergic blocking agents, including prazosin, yohimbine and phentolamine, inhibited the occurrence of ventricular fibrillation. As shown in Fig. 5, OPC-18790 tended to decrease blood pressure both when administered alone and when administered in combination with dopamine, thus indicating that OPC-18790 does not stimulate $\alpha$-adrenoceptors and may even block them (OPC-18790 inhibits $\left[{ }^{3} \mathrm{H}\right]$ prazosin binding, our unpublished data). OPC-18790 has a coronary blood flow-increasing action (2), and this is also beneficial in decreasing the occurrence of arrhythmias that might result from dopamine's coronary vasoconstriction. In addition, excess accumulation of cyclic AMP in ventricular cells may be related to arrhythmogenicity (19), and the increase in cyclic AMP level by the combination of OPC-18790 and dopamine might be smaller than that by increasing the dose of dopamine; the difference in the intracellular cyclic AMP level might produce the difference of occurence of arrhythmias.

The development of arrhythmias is often observed in patients with congestive heart failure. Since recent studies using Holter monitoring in patients with heart failure demonstrated that nonsustained ventricular tachycardia was seen in about $50 \%$ of the patients $(20-22)$, it is necessary to carefully monitor for the occurences of arrhythmias when using cardiotonic agents, even those having weak arrhythmogenicity.

In conclusion, OPC-18790 administration in combination with dopamine increased cardiac output and LVdP $/ \mathrm{dt}_{\max }$ with no major changes in heart rate, arterial blood pressure or arrhythmias. High doses of dopamine increased systolic blood pressure and caused severe ventricular arrhythmias. The combination of dopamine and OPC-18790 supplemented the positive inotropic effects without increasing the occurrence of arrhythmias, indicating that such combined use may provide new therapeutic options for the treatment of patients with heart failure. 
Acknowledgment

We would like to thank Mr. Keiji Kakumoto (Tokushima Research Institute, Otsuka Pharmaceutical Co., Ltd.) for statistical analysis of the data.

\section{REFERENCES}

1 Fujioka $T$, Teramoto $S$, Mori $T$, Hosokawa $T$, Sumida $T$, Tominaga $M$ and Yabuuchi $Y$ : Novel positive inotropic agents: Synthesis and biological activities of 6-(3-amino-2-hydroxypropoxy)-2(1H)-quinolinone derivatives. J Med Chem 35, $3607-3612$ (1992)

2 Hosokawa T, Mori T, Fujiki H, Kinoshita S, Takemoto K, Imaizumi $T$, Noda $T$, Ohura $M$, Tominaga $M$ and Yabuuchi Y: Cardiovascular actions of OPC-18790: A novel positive inotropic agent with little chronotropic action. Heart Vessels 7, 66-75 (1992)

3 Itoh $\mathrm{S}$, Mori $\mathrm{T}$, Tominaga $\mathrm{M}$, Ishikawa $\mathrm{M}$, Koga $\mathrm{K}$ and Yabuuchi Y: Differential effects of OPC-18790, amrinone and dobutamine on cardiac function and energy metabolism in the guinea pig isolated ischemic heart. Br J Pharmacol 114, $1090-1096$ (1995)

4 Ishikawa M, Mori T, Itoh S, Fujiki H, Koga K, Tominaga M and Yabuuchi Y: Effects of OPC-18790, a new positive inotropic agent, on energetics in the ischemic canine heart: a ${ }^{31}$ P-NMR study. Cardiovasc Res 30, 299-306 (1995)

5 Fujiki $\mathrm{H}$, Mori $\mathrm{T}$, Hosokawa $\mathrm{T}$, Tominaga $\mathrm{M}$ and Yabuuchi $\mathrm{Y}$ : OPC-18790, a newer positive inotropic agent, improves experimentally induced heart failure in the dog. Jpn $\mathbf{J}$ Pharmacol 55, Supp I, 158P (1991)

6 Sugioka $M$, Ito $M$, Masuoka, $H$, Ichikawa $K$, Konishi $T$, Tanaka $T$ and Nakano $T$ : Identification and characterization of isozymes of cyclic nucleotide phosphodiesterase in human kidney and heart, and the effects of new cardiotonic agents on these isozymes. Naunyn Schmiedebergs Arch Pharmacol 350, $284-293$ (1994)

7 Endoh M, Kawabata Y, Katano Y and Norota I: Effects of novel cardiotonic agent ( \pm )-6-[3-(3,4-dimethoxy-benzylamino)2-hydroxy-propoxy]-2(1H)-quinolinone (OPC-18790) on contractile force, cyclic AMP level, and aequorin light transients in dog ventricular myocardium. J Cardiovasc Pharmacol 23, $723-730$ (1994)

8 Kondo N, Shibata S, Kodama I and Yamada K: Electrical and mechanical effects of amrinone on isolated guinea pig ventricular muscle. J Cardiovasc Pharmacol 5, 903-912 (1983)

9 Wu ZJ, Awaji T, Abe H, Motomura S and Hashimoto K: Effects of OPC-18790, a new positive inotropic agent, on canine ventricular arrhythmias. Jpn J Pharmacol 63, 399-404 (1993)
10 Merin RG, Kumazawa T and Luka NL: Myocardial function and metabolism in the conscious dog and during halothane anesthesia. Anesthesiology 44, 402-415 (1976)

11 Katz RL and Epstein RA: The interaction of anesthetic agents and adrenergic drugs to produce cardiac arrhythmias. Anesthesiology 29, $763-784$ (1968)

12 Hashimoto $\mathrm{K}$ and Hashimoto $\mathrm{K}$ : The mechanism of sensitization of the ventricle to epinephrine by halothane. Am Heart J 83, 652-658 (1972)

13 Sato T, Washizu M, Kobayashi K, Misaka K, Hayashi T, Orima $\mathrm{H}$ and Motoyoshi S: Arrhythmogenicity of dopamine and its effects on hemodynamics in dogs under halothane anesthesia. Jpn J Vet Sci 51, 396-402 (1989)

14 Goldberg LI: Cardiovascular and renal actions of dopamine: Potential clinical applications. Pharmacol Rev 24, 1-29 (1972)

15 Thandroyen FT, Worthington MG, Higginson LM and Opie LH: The effect of alpha- and beta-adrenoceptor antagonist agents on reperfusion ventricular fibrillation and metabolic status in the isolated perfused rat heart. J Am Coll Cardiol 1, $1056-1066$ (1983)

16 Hashimoto K, Haruno A, Matsuzaki T, Sugiyama $A$ and Akiyama K: Effects of antiarrhythmic drugs on canine ventricular arrhythmia models: Which electrophysiological characteristics of drugs are related to their effectiveness? Cardiovasc Drug Ther 5, 805-818 (1991)

17 Katz AM: Potential deleterious effects of inotropic agents in the therapy of chronic heart failure. Circulation 73, III-184-III190 (1986)

18 Hashimoto K, Haruno A, Matsuzaki T, Hirasawa A, Awaji T and Uemura Y: Effects of new class III antiarrhythmic drug (E-4031) on canine ventricular arrhythmia models. Asia Pacific J Pharmacol 6, 127-137 (1991)

19 Lubbe WF, Podzuweit T and Opie LH: Potential arrhythmogenic role of cyclic adenosine monophosphate (AMP) and cytosolic calcium overload: Implications for prophylactic effects of betablocker in myocardial infarction and proarrhythmic effects of phosphodiesterase inhibitors. J Am Coll Cardiol 19, 1622- 1633 (1992)

20 Meinertz T, Hofmann T, Kasper W, Treese N, Bechtold $H$, Stienen U, Pop T, Leitner E-RV, Andresen D and Meyer J: Significance of ventricular arrhythmias in idiopathic dilated cardiomyopathy. Am J Cardiol 53, $902-907$ (1984)

21 Huang SK, Messer JV and Denes P: Significance of ventricular tachycardia in idiopathic dilated cardiomyopathy: observation in 35 patients. Am J Cardiol 51, 507-512 (1983)

22 Maskin CS, Siskind SJ and LeJemtel TH: High prevalence of nonsustained ventricular tachycardia in severe congestive heart failure. Am Heart J 107, 896-901 (1984) 